\title{
DISORDERS OF SPOKEN LANGUAGE IN YOUNG CHILDREN*
}

BY

\author{
MARY D. SHERIDAN \\ Medical Officer, Ministry of Health
}

(RECEIVED FOR PUBLICATION APRIL 22, 1960)

A number of papers by British authors concerning defects of speech in childhood have recently appeared, notably those of Worster-Drought (1957), to whom all workers in this field owe an outstanding debt, Morley, Court and Miller (1955), Walker and Languth (1956) and Ingram (1959). This paper is concerned with disorders of spoken language in young children.

\section{Definition of Terms}

The relevant terminology is confused. In a previous paper (Sheridan, 1959), I offered my own definitions. Language is the symbolization of thought in speech, gesture or writing for the purpose of interpersonal communication. Speech is the use of systematized vocalizations to express verbal symbols or words. Hearing is the reception of sound by the ear and its transmission to the primary auditory area of the cortex. Listening is the act of paying attention to the sounds received with the object of interpreting their meaning. Interpretation of spoken language depends upon previous learning, that is upon the gradual building up of an efficient memory register, to which incoming words can be referred for matching, i.e. recognition, and from which needed words can be summoned at will, i.e. recall.

Between infants and their mothers a prelinguistic interpersonal communication can be seen which expresses itself in clinging or nestling, in resistive stiffening or furious bodily activity and in unorganized but emotion-charged vocalizations. It is concerned with the direct expression of basic feelings and needs. Later the non-speaking toddler pulls his mother where he wishes her to go, places her hand on an object he desires, points urgently with his finger, smiles, strokes her face caressingly, or throws a tantrum. This primitive form of communication deserves closer study than it has yet received, because when symbolic language fails

* A paper read to Paediatric Section of the Royal Society of Medicine, February 26, 1960. him the child must resort to it in order to maintain contact with his fellow beings.

\section{Spoken Language}

Spoken language implies communication between two brains, or rather two minds. Without entering into discussion concerning the age-old problem of the relation of brain to mind, it can be agreed that mental processes are in some way mediated in the brain. The brain also controls the functional activity of the organs which produce sounds of speech and those which receive sounds made by other people. The function of the brain with regard to spoken language is, therefore, threefold, to receive, to interpret and to express.

Reception depends primarily upon hearing. Unlike the eye, the ear can never 'close down', nor has it any power of selection, but must transmit to the first auditory station in the temporal lobe, through a complicated chain of connexions, whatever medley of sounds is received by the cochlea. From then onwards the mind takes charge. Having decided to listen it proceeds to select the significant or 'foreground' speech elements from the general background of noise, arranges them in orderly groups and finally in the light of intellect and the warmth of emotion interprets their meaning. Interpretation depends upon many stored memories not only of the verbal symbols themselves and of the people, objects, activities and trains of thought which they represent, but also of the countless emotions which invest them. As we go through life, every spoken word adds to its fundamental of meaning many overtones of implication. Expression is inaugurated by the mind's decision to reply, after which comes the marshalling of relevant ideas and their formulation in language, then the appropriate kinaesthetic assembly, and finally, the motor impulse which puts the required muscles in action to produce results in time, tune and stress. The process is not yet over, however, because as the listener 
receives his message, the speaker simultaneously receives a feed-back into his own central nervous system of a host of stimuli, auditory, vibratory, kinaesthetic, visual, emotional and thought-productive.

Whether or not these mental steps have neurological equivalents, we know from experience that delay or blocking can occur at any one of these levels as a result of functional preoccupation or structural disablement. The received patterns of vocal sounds may be imperfect; willingness to listen may be absent; ability to comprehend may have been lost and so on.

In their recent book, Speech and Brain-mechanisms, Penfield and Roberts (1959) have described three regions in the cortex of the dominant hemisphere (usually the left) which they have outlined with electrodes, and which they believe to be concerned with 'ideational speech'. They consider that the 'interpretative cortex' is adjacent to the $3 \mathrm{rd}$ or posterior of these speech areas, i.e. is situated in the temporal and inferior parietal regions. They further report:

'In a child a major lesion of the posterior speech cortex would produce a transfer of the whole speech mechanism to the opposite hemisphere. Examples of completely successful transfer of speech mechanisms from the left to the right hemisphere of children under three or four years of age are numerous. The upper age limit is not certain ...'

and, of great interest to those concerned with the special learning difficulties of brain-injured children, they consider the lesions of the corresponding area in the non-dominant hemisphere are associated with 'loss of awareness of the body scheme and of the spatial relationships around him'.

\section{The Acquisition of Spoken Language}

The normal acquisition in early childhood of all the biologically determined skills, i.e. locomotion, manipulation, visual discrimination, listening, speaking and social adjustment, depends upon timely opportunity to explore, experiment with and learn to understand the world around him, and to realize how he relates to other people. Upon these spontaneously acquired skills the later attainment of all voluntarily acquired expertise depends. The child instinctively recognizes this. During every moment of his waking day he is impelled to practise and improve his techniques. If, through congenital disability or environmental deprivation, the normal methods of learning and communication are not available to him, he must substitute whatever means are open to him or fail to develop his personality and his intellect.

This biological learning appears to reach its zenith in the first two or three years of life, concurrently with the rapid growth and maturation of the brain, and gradually tapers off by the age of 6 or 7 years, after which habits of functioning appear to be firmly fixed.

Richter (1959) has offered biochemical evidence. He describes a gradual change from one metabolic pattern to another as the 'metabolism of growth' is replaced by the metabolism of mature functioning.

'There are critical periods during which in the C.N.S. new enzymes appear, increase in activity and later decline ... The normal development of nerve cells appears to depend on their receiving a sufficient amount of physiological stimulation during growth.'

Ritchie Russell (1959) has described the acquisition of language in neurological terms.

'It is clear that the method first used in early childhood will probably persist throughout life so that the early months of life are the most important for the planning of the brain mechanisms. Further, the neuronal patterns used to learn a word in early childhood will probably be the same as those used in old age.'

Although every child proceeds at his own pace, he must travel from one stage of development to the next by the same stepping-stones. The sensory stimuli from which the child learns are highly complex. They are composed of a dominant sensation and several supplementary ones. For instance, in learning a spoken word the child not only hears it but sees it on his mother's lips and when he is held in her arms feels the vibration of its vocal resonance. He also hears the accompanying cadences of her voice and sees the expression on her face. The child with impaired hearing must rely more heavily than does the normal child upon these supplementary clues.

The reasons for delay or failure in the development of spoken language are not easy to sort out. My own classification is a broad one but even so there is considerable overlapping. Nevertheless, I have found it useful in history-taking and in hopefully guiding treatment towards the next developmental stepping-stone:

Lack of opportunity to learn;

Impaired hearing;

Low intelligence;

Delayed maturation of the central nervous system; Brain injury;

Psychogenic disorders;

Motor dysfunctions;

Lesions of the peripheral speech organs. 
This paper discusses some aspects of faulty reception and interpretation.

Opportunity to Learn. The first of our duties to the growing mind is to provide it with stimulation.

The normal baby reacts reflexly to sounds from birth. He hears, but cannot yet listen. His brain is potentially conscious but has everything to learn. Within a few weeks he shows signs of awareness of the person who takes care of him. The world he perceives gradually expands in space and in time, so that, at first capable of paying only momentary heed to happenings within a few inches of his eyes and ears, he is soon able to bestow prolonged and selective attention on objects and events within several feet. Literally he learns to feel, hear and speak on his mother's knee. He comes to associate the touch of her hands, the sight of her face, and the cadences of her voice with the comfort she brings him. At 3 months his immediate response to the near-by human face is to smile, activate and vocalize with pleasure. As Rheingold, Gewirtz and Ross (1959) have shown, these vocalizations are reinforced or extinguished according to the vocal response of the adult. During the first year of life the child receives continual auditory stimulation close to his ear, at high decibel level, in words which are addressed personally to him, and which concern events which affect him directly in the here and now. At the same time he is given strong encouragement to vocalize in return. This intensive individual coaching in the mother-tongue must be given at motherdistance and in the critical period if the child is to acquire fluency in the use of spoken language, otherwise the difficulties of learning to hear and speak are increased not only by diminution of sensory stimulus in time and space, but also by attenuation of emotional rapport. The emotional messages of speech depend upon countless delicate variations of vocal tune and stress. Before the advent of hearing aids, deaf children can have had little conception of the emotional overtones accompanying vocal utterance.

Impaired Hearing. The child speaks as he hears. Speech sounds in common with other varieties of sound possess attributes of pitch, intensity and duration. The human ear is capable of hearing about 10 octaves in pitch. The speech range covers some $7 \frac{1}{2}$ octaves from about 100 to 10,000 cycles per second. The frequencies below 1,200 provide most of the energy, resonance and emotional colour of speech, while those above 1,200 cycles are concerned mainly with its intelligibility (Fry, 1957). The chief characteristic components of the vowel sounds are in the lower and middle speech frequencies, the sound $/ 00 /$ being the lowest in pitch and the sound $\mid e e /$ the highest. The chief components of the consonant sounds are in the middle and high frequencies. The fundamental notes of the nasal sounds $/ m / n / n g$ border on the low frequencies, the continuants $|r| l|w| y$ are somew hat higher in pitch, the plosives $/ d / g / t / k$ still higher and the fricatures $/ v / f / t h$ highest of all. The fundamental vowel pitch of a woman's voice is about an octave higher than a man's. Children's voices are still higher.

Vowel sounds possess the strongest decibel intensity as well as being lowest in pitch and are therefore responsible for the carrying power of speech. The consonants are weaker in intensity but more distinctive in character and are therefore chiefly responsible for intelligibility. The average speaker's voice varies about 30 decibels in intensity between the vowel sound $/ a w /$ which is the strongest and the voiceless consonant $/ t h /$ which is the weakest phonetic unit.

The ability to comprehend spoken language therefore necessitates the capacity to hear and interpret a sequence of complicated sounds which vary rapidly by $7 \frac{1}{2}$ octaves in pitch and 30 decibels in intensity, and of which the individual units endure only a fraction of a second. It will be obvious that impaired hearing over any part of the speech range, and particularly over the high (consonant-carrying) tones, will lead to delay in the development of speech. Severe loss over the middle and lower frequencies will prevent its spontaneous acquisition altogether. The danger of wrongfully deeming children with impaired hearing mentally retarded must never be forgotten (Sheridan, 1944). Provided the interpretative faculties are intact the young child can make excellent use of a very imperfect field of hearing, but only if he is given expert auditory training, and an efficient hearing aid, in the critical period (Whetnall, 1956, 1958; Ling, 1959). The importance of following up all infants 'at risk', and of early diagnosis, cannot therefore be overstressed (Ballantyne, 1959). The need to compensate for the period of auditory deprivation previous to diagnosis must always be explained to the parents. Otherwise they will be disappointed and perhaps fail to persevere because the child does not begin to speak immediately he is fitted with an aid.

It will be obvious that the deaf child's difficulties are enormously increased if his disability is associated with a defect of central auditory perception. Such cases are fortunately rare although so-called 'oral failures' may be found in most schools for the 
deaf. But when it is established that a child is incapable of associating spoken words with meaning he must be given alternative methods of communication, e.g. by writing, finger-spelling or gesture.

Mental Retardation. Mentally backward children are always late in acquiring spoken language. Their infantile vocalizations may also be delayed and are usually meagre in quantity, although they are normally inflected. When inferior genetic endowment is complicated by impaired hearing or organic brain lesions, no matter how minor in degree, language disability is seriously increased. Even when these children possess normal hearing, if they have acquired locomotion before they have had time to store their slow minds with the requisite auditory memories at mother-distance, they must be afforded further opportunities to learn. This implies patient, individual language-training by affectionate and understanding adults using simple words, at close quarters and in homely situations. Otherwise they are denied the possibility of fully developing what faculties they possess. The young mentally handicapped child presents a challenge to the skill and compassion of paediatricians in hospital and public health alike. Too many of these unfortunate children, who could be cared for and trained in the community if more attention were devoted to their problems, and to their parents' difficulties, are at a tender age still referred for admission to large residential institutions.

The speech of young educationally sub-normal children is usually defective, and their language always impoverished. In the past speech therapists were understandably reluctant to accept them for treatment. Many of those who are now willing to undertake responsibility for training them have little previous experience with retarded children and, working unguided and in isolation, tend to expend their energies in speech correction rather than in language development. Renfrew (1959) has made a study of the subject and in a recent valuable paper describes methods of treatment. More vigorous medical and psychological research into the whole problem is needed.

The 'Developmental Aphasias'. In the next group of children delay in acquisition of spoken language is thought to be due to a maturational lag in that part of the central nervous system which deals with span of auditory attention and with language formulation. These late talkers are usually boys, who are normally developed in other respects. Their hearing is good and on performance tests they show average intelligence. They comprehend what is said to them, especially when short, simple sentences are used, but in reply they use only single words or fragmentary phrases helped out with gestures. They are often shy because they realize their social disability but they are friendly and co-operative once their confidence is won. There is frequently a family history of delayed speech. They usually begin to talk at about $3 \frac{1}{2}-4$ years of age and then rapidly catch up with their contemporaries, without any apparent damage to their personality or to their ultimate scholastic achievement.

More complex forms of this 'developmental aphasia' or dysphasia sometimes occur. Although they are rare, cases crop up in the experience of every paediatrician and otologist. These children show no auditory loss for faint noises or pure tones, and their intelligence on performance tests may be average, but they are slow to attach meaning to everyday sounds, and particularly to spoken words. Their speech, when it eventually appears at about $3 \frac{1}{2}$ to 5 years, is often severely defective in articulation and syntax. They rarely become fluent conversationalists. Some show slight motor clumsiness. Many have special learning difficulties with regard to reading, writing, spelling and drawing. The condition (or group of conditions) has been variously described as auditory imperception, word deafness, strephosymbolia or dyslexia according to the chief presenting symptom. There is sometimes a history of difficult birth, serious illness in the first years of life or frank head injury, so that it is tempting to hypothesize neurological damage rather than developmental delay. Many of the children appear to recover spontaneously, or perhaps learn tricks to circumvent their difficulties, by 9 or 10 years. The condition merits further, co-ordinated investigation.

Brain Injuries. Brain damage causing language disorder may result from birth traumas or defects of cellular metabolism in the perinatal period and, in later infancy and childhood, from cerebral inflammations or head injuries. It is often impossible to decide whether the gross language disorders which occur in the cerebral palsies are the result of damage to the auditory, motor, or interpretative functions of the brain, or to combinations of all these. Many of these children suffer from additional handicaps, such as deafness, eye defects, epilepsy, mental retardation, specific learning difficulties, disturbances of the body image and problems of behaviour. In other cases of confirmed or suspected brain injury motor disabilities may be slight or absent, and the presenting symptoms are learning difficulties, problems of behaviour, or 
language disorders. All types of brain-injured children, however, have one characteristic in common. They tend to show, from day to day, a baffling inconsistency of response to testing procedures and to therapy, so that one is driven to the conclusion that essential connexions between the various brain mechanisms sometimes function and sometimes do not.

The whole question of speech therapy in cerebral palsy needs review. At present much time and energy are devoted to procedures which appear to be entirely empirical and almost exclusively concerned with improvement of articulation. Study of the available literature and discussions with many experienced speech therapists have brought me no nearer to understanding the fundamental neurological concepts which presumably underlie the practical procedures employed. Nor is it easy to assess results. The therapists' time might be more profitably spent in devising improved methods of communication for each individual child and in giving appropriate instruction to his parents and teachers. Detailed investigation and long-term follow-up of series of cases in association with paediatric neurologists and psychologists is urgently required. It is vitally important to discover whether or to what extent spoken language that is intelligible to the average listener can be produced by training, if it has not already begun to appear spontaneously by 7 years, and whether before or after this age alternative means of communication should be sought. It is true that the dysarthria of cerebral palsy usually improves in parallel with the general improvement in neuromuscular control. Squints also tend to improve, but the associated amblyopia may be irreversible.

Psychogenic Disorders. The disorders of spoken language which occur in the schizophrenias of childhood are only part of a grossly distorted development of intellect and personality. They vary from complete absence of speech to the use of neologisms, echolalia, or marked peculiarities of vocal intonation and stress. The one constant finding is an inability to use speech as a means of interpersonal communication. Language symbols seem to be lacking, although naming and parrot-like repetition may be retained. It is as if the child has the capacity to recognize and to repeat word forms but not to recall word meanings. $\mathrm{He}$ appears to be imprisoned in, or to have retreated to a small, insecure, and sometimes terrifying pre-linguistic, pre-bodyimage world of his own, from which he can only reach out in a fragmentary way to make contact with other people. His play is also solitary, meaningless, and non-progressive. I have not had the opportunity to observe groups of non-speaking psychotic children over a prolonged period of time, but in visits to hospitals and special units I have never seen them engage in the meaningful makebelieve play normal nursery school children so richly invent, and which, in more primitive form, engrosses the attention of little mongols when they are given appropriate opportunities. The age when spoken language appears in psychotic children is of considerable prognostic significance. Kanner and Eisenberg (1955) have recently reported, in a longterm follow-up of 40 psychotic children, that of 19 who were not speaking by the age of $4 \frac{1}{2}$ years, only one subsequently did so. I cannot myself recollect ever seeing a child who had not begun to use spoken language by 6 years who later spontaneously developed it.

\section{Conclusions}

Given normal opportunity to learn, recognizable spoken words may be expected to appear between 14 and 20 months and by $2-2 \frac{1}{2}$ years the child is usually putting words together to make little sentences. The commonest causes of delay in the development of spoken language are deafness and mental backwardness. Full expert assessment of the hearing and the intelligence is, therefore, the first step in differential diagnosis. Regarding the rarer causes of delay it needs to be remembered that lesions of the central nervous system occurring in the first few years of life have been inflicted on plastic and rapidly growing tissues, and only time can tell whether the resulting damage is permanent, or capable of compensation, or open to recovery.

The first five or six years are therefore critical for diagnosis, treatment and training. However unpromising he may at first sight appear to be, the young child handicapped by a disorder of spoken language should be given the benefit of expert advice and supervision during these vitally important early years. Otherwise, lacking the means of communicating with his fellow beings, he may be condemned for the remainder of his life to emotional solitude and intellectual silence.

\section{REFERENCES}

Ballantyne, J. C. (1959). The early diagnosis of congenital deafness. Proc. roy. Soc. Med., 52, 917

Fry, D. B. (1957). Speech and language. J. Laryng., 71, 434.

Ingram, T. T. S. (1959). A description and classification of the common disorders of speech in children. Arch. Dis. Childh., 34, 444.

Kanner, L. and Eisenberg, L. (1955). Notes on the follow-up studies of autistic children. In Psychopathology of Childhood, ed. P. H. Hoch and J. Zubin, p. 227. Grune and Stratton, New York.

Ling, D. (1959). Some results of auditory education in a special class for children with defective hearing. Proc. roy. Soc. Med., $52,925$. 
Morley, M., Court, D. and Miller, H. (1955). Delayed speech and developmental aphasia. Brit. med. J., 2, 463.

Penfield, W. and Roberts, L. (1959), Speech and Brain-mechanisms,

pp. 202, 204, 240. Princeton University Press, Princeton.
Renfrew, C. E. (1959). Speech problems of backward children. Speech Path. Ther., 2, 34.

Rheingold, H. L., Gewirtz, J. L. and Ross, H. W. (1959). Social conditioning of vocalizations in the infant. $J$. comp. physiol. Psychol., 52, 68.

Richter, D. (1959). Protein metabolism of the brain. Brit. med. J., 1,1255 .

Russell, W. Ritchie (1959). Brain, Memory, Learning, p. 82. Clarendon Press, Oxford.
Sheridan, M. D. (1944). High-tone deafness in schoolchildren simulating mental defect. Brit. med. J., 2, 272.

(1959). Delay or failure in the development of spoken language. Proc, roy. Soc. Med., 52, 913.

Walker, C. H. M. and Languth, P. R. (1956). Developmental speech anomalies in apparently normal children. Brit. med.J., 2,1455 .

Whetnall, E. (1956). The management of deafness in the young child. Proc. roy. Soc. Med., 49, 455.

- (1958). The deaf child. In Recent Advances in Paediatrics, 2nd ed., $\in$ d. D. Gairdner, p. 329. Churchill, London.

Worster-Drought, C. (1957). Observations on speech disorders in children. Postgrad. med. J., 33, 486. 